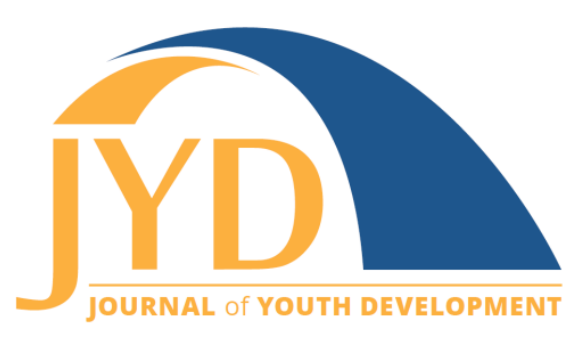

http://jyd.pitt.edu/ | Vol. 15 Issue 1 DOI 10.5195/jyd.2020.814 | ISSN 2325-4017 (online)

\title{
Advancing Academic Pathways for Building Capacity in the Youth Development Profession
}

\author{
William H. Quinn \\ Department of Parks, Recreation, and Tourism Management, Clemson University \\ wquinn@clemson.edu
}

\section{Barry A. Garst}

Department of Parks, Recreation, and Tourism Management, Clemson University bgarst@clemson.edu

\section{Edmond P. Bowers}

Department of Parks, Recreation, and Tourism Management, Clemson University edmondb@clemson.edu

\section{Kayla L. Weston}

Department of Parks, Recreation, and Tourism Management, Clemson University kweston@clemson.edu

\begin{abstract}
The growing literature on the theory and practice of youth development provides a framework for youthserving practitioners to design, implement, and grow youth programs in their communities. Yet such a framework is not widely known in many youth-serving organizations where professional development is variable. The youth development field would benefit from academically trained professionals who could apply the youth development literature to serve youth more effectively in organizations or communities. The purpose of this article is to describe a graduate level academic degree program in youth development in order to increase awareness of the importance of intentional leadership in youth programs and bring attention to the fundamental learning structures that can be deployed to build human capacity in the youth development field. The history, theoretical frameworks, and structure of the program are briefly described. Details are provided on 4 effective features of this academic degree program rated by students and graduates as being valuable components of the program. Applications to youth development practice are explored.
\end{abstract}

Key words: youth development, academic degree programs, higher education, online learning

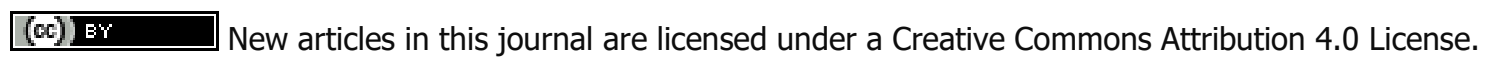
This journal is published by the University Library System, University of Pittsburgh and is cosponsored by the University of Pittsburgh Press. The Journal of Youth Development is the official peer-reviewed publication of the National Association of Extension 4-H Youth Development Professionals and the National AfterSchool Association. 


\section{Advancing Academic Pathways}

\section{Introduction}

The growing literature on the theory and practice of youth development provides a framework for youth-serving practitioners to design, implement, and expand youth programs in their communities (Deutsch, Blyth, Kelley, Tolan, \& Lerner, 2017; Roth \& Brooks-Gunn, 2016). However, the youth development field would benefit from academically trained professionals who could deploy the youth development literature to serve youth more effectively in organizations or communities in which such leadership is ineffective or limited (Mahoney \& Warner, 2014). The purpose of this article is to describe a graduate level academic degree program in youth development at Clemson University and increase awareness of the importance of building human capacity in the youth development field. In addition, fundamental learning structures of the program that serve as a vehicle for building such capacity in the youth development field are described. The history of the program is detailed and established outcomes are identified. Finally, we highlight four effective features of this academic degree program as identified by program graduates and discuss applications to youth development practice.

\section{The Profession of Youth Development}

In this article "youth development" is defined based on the Interagency Working Group on Youth Programs' definition as "an intentional, prosocial approach that engages youth within their families, peer groups, schools, organizations, and communities in a manner that is productive and constructive; recognizes, utilizes, and enhances youth's strengths and assets; and promotes positive outcomes for young people by providing opportunities, fostering positive relationships, and furnishing the support needed to build on their leadership strengths" (Dymnicki et al., 2016, p. 4). Further, this article defines the youth development field as comprised of "anyone who develops/implements places/programs designed to fill the discretionary time of young people with opportunities for socialization and learning" (Borden, Schlomer, \& Wiggs, 2011, p. 128). A critical factor influencing the growth of the field of youth development is the expansion of academic degree-granting programs (Borden, Craig, \& Villarruel, 2004; Garst, Weston, Bowers, \& Quinn, 2018; Mahoney \& Warner, 2014). As part of this growth, strengthening the out-of-school time (OST) work force is an essential challenge tasked to the field of youth development to promote child learning and well-being (Blattner \& Franklin, 2017). Current challenges with the OST work force include staff turnover and lack of education and experience (Asher, 2012; Khashu \& Dougherty, 2007). The OST workforce plays a strategic role as an educational resource for youth. However, staff members frequently view 


\section{Advancing Academic Pathways}

themselves as ill-prepared or in transient positions that may not be central to their career path (Ravazi, 2007; Richardson, 2012).

Professionalization of the OST workforce, and the accompanying benefits, has been cited as a way to reduce these perceptions and turnover rates among the workforce (Borden et al., 2011). Professional development, defined as "educational opportunities meant to enhance the competences [sic] of youth program providers" (Garst, Baughman, \& Franz, 2014, p. 3), is an important strategic mission for OST organizations (Bradshaw, 2015; Cole, 2011; Cooper, 2013). Hence, the provision of high-quality professional development has the potential to improve program content by enhancing adult leadership while nurturing stronger and more supportive youth settings (Borden et al., 2011; Johnson, Rothstein, \& Gajdosik, 2004; Mahoney \& Warner, 2014). Yet, professional development opportunities for youth workers and leaders in OST are diverse (Bowie \& Bronte-Tinkew, 2006), and no universal certification or license for OST program providers exists (Cole, 2011; Gabrieli, 2011; Stonehill, et al., 2011). Therefore, the professional development opportunities available to the OST workforce often vary in quality, and the support for and recognition of staff participation in these opportunities, irrespective of quality, varies greatly across programs at the local and national level (Yohalem, Pittman, \& Moore, 2006). Efforts to provide professional development pathways of high quality and with established standards of recognition could greatly benefit the youth development field.

\section{Role of Academic Degree Programs in Supporting the Youth Development Field}

There is support for the development of academic programs to build human capital to initiate and grow youth development-based organizations in communities (Borden et al., 2004; Garst et al., 2018). Primary youth environments in which human capital is needed are in OST programs that may have varied missions and diverse youth skill-building goals embedded in unique environments. Three contemporary issues in the youth development field provide support for an academically prepared youth workforce. First, an ongoing policy debate regarding the central focus of OST programs accompanies concerns about poor program attendance (Leos-Urbel, 2015). Bolstering the youth development profession would require an increase of youth development professionals to participate in such debates or controversies. Policy debate is demanded on variables that influence the effectiveness of OST programs given the attention, resources, and needs that continue to grow in OST programming (Leos-Urbel, 2015). Yet, qualified youth development professionals who have skills to apply theoretical ideas central to youth development (e.g., positive youth development; asset-building; resilience; risk and protective factors) or technical skills (e.g., program development; assessment and evaluation; 


\section{Advancing Academic Pathways}

grant writing; leadership) are not routinely available or included in shaping and implementing mission clarity, programming decisions, or community-building strategies due to insufficient professional preparedness as well as trends that suggest a decline in the number of professional development opportunities being made available (Gerdes, Durden, Mincemoyer, \& Lodl, 2013). Thus, to successfully effect positive change in youth, more professionally prepared staff are needed (Blyth, 2011; Bowie \& Bronte-Tinkew, 2006).

A second issue is that youth-serving organizations frequently engage in community-based partnerships with educational institutions, summer camps, volunteer organizations, parks and recreation departments, non-profit organizations, and other entities (Finn-Stevenson, 2014). Therefore, there is high need for academically-trained youth development professionals who have an understanding of the value of local partnerships, strategies for mobilizing resources, approaches for building on successes and negotiating threats, and, importantly, the processes that contribute to or deter successful partnership outcomes (Byrne \& Hansberry, 2007). For example, in a study of a citywide summer learning program with over 10,000 students and 12 different school districts across two states, researchers examined qualities and practices associated with successfully implementing an effective program as well as gaps and limitations in the field (Hall, Poston, \& Dennehy, 2017). Study authors found that researchers generally agree on several core structural components necessary to design and implement effective summer learning experiences. The authors reported on qualities of successful partnerships; yet, such knowledge is not likely to be universally known or shared in the universe of youth-serving organizational settings. That is, knowledge provided in these types of studies in the absence of youth development professionals who may serve as leaders or staff at sites such as those examined by Hall and colleagues is not as well utilized to inform valid decisions as it could be. Therefore, resources may be used inefficiently in some summer camp initiatives due to the possibility that some youth-serving sites may not have leaders sufficiently prepared to utilize the available body of literature on youth development.

A third and final example here is the importance of designing culturally responsive organized out-of-school time activities for youth across settings. To be most effective, youth organizational activities need to meet high-quality standards (Simpkins, Riggs, Ngo, Vest Ettekal, \& Okamoto, 2017). The eight features of quality development by the National Research Council's Committee on Community-Level Programs have been largely defined as universal development needs. However, some or most of these features do not sufficiently address growing ethnic and racial diversity in community settings. Simpkins et al. (2017) delineate 


\section{Advancing Academic Pathways}

strategies that address all eight features to support after-school activities to be more culturally responsive and address specific needs of these youth who participate in such activities. Successful youth development professionals need to be well-versed in this theoretical, empirical, and practical evidence to complement the "real-world" knowledge they gain through working in programs (Mahoney \& Warner, 2014).

The purpose of this paper is to describe a graduate degree program in Youth Development Leadership that addresses the competencies identified above and several related core knowledge areas that build the youth development field through academic preparation. The result of such degree programs might boost the likelihood of increased effective collaborations to make policy and program decisions that strengthen youth programming in communities. Subsequently, such collaborations would draw more resources based on best practices and other known factors of youth organization success while contributing to greater efficiency of available resources.

\section{Clemson University Youth Development Leadership (YDL) Graduate Program}

In 2002, a consortium of faculty at Clemson University representing education, human development, family science, parks and recreation, sociology, and psychology initiated a collaboration to explore a degree for professional youth development leaders to promote the well-being and success of young people. This initiative was intended to strengthen youthserving organizations by preparing professionals with leadership skills to reflect the growing movement in positive youth development (Lerner et al., 2013). To be leaders of organizations, it was determined that a graduate-level program would be optimal for preparing such professionals.

The youth development graduate degree program was established in 2004 with the first M.S. Youth Development Leadership cohort enrolled in 2006 at Clemson University. The origin of the program is derived from a dean and faculty who collectively had a long work history of professional youth development collaborations and viewed an academic program to prepare youth development professionals as both needed and possible (Garst, Bowers, Quinn, \& Gagnon, 2016). It was believed that a market existed for the creation and implementation of a pedagogy that centered on the positive youth development framework (Lerner et al., 2013) using innovative online instructional technologies for delivering content as well as facilitating peer interaction. Because there was no accrediting body for youth development programs which would guide curriculum development and course offerings, the program architects loosely based 


\section{Advancing Academic Pathways}

the curriculum on the Core Knowledge and Competencies of the National AfterSchool Association (NAA, 2019), developed to provide the profession with a body of knowledge, skills, a code of ethics, and public recognition to demonstrate expertise to, and credibility of, educational institutions. Further, the program was designed with several key features, including: (a) an online format to serve currently working youth development professionals; (b) content that reflects a qualitatively different approach to prepare those who seek to enter the profession and those in the profession who desire opportunities for advancement; and (c) a structure and sequence to coursework that foster high student engagement, retention, and professional preparation.

\section{Program History and Structure}

Clemson University was an early adopter of online education technologies and methodologies. The faculty envisioned that such an approach would accommodate current youth-serving professionals who, as nontraditional students (e.g., professionals working full- or part-time while also pursuing an academic degree), would not be willing or expected to leave a job or uproot their families to move to campus. This target population was also viewed as the professionals who would find this curriculum to be useful as knowledge and content that could be immediately applied to their work with youth. This target population would also have the most immediate impact on the field of youth development. The rapid evolution of online learning technologies would accommodate such working professionals so that the Clemson University program could offer a blended online learning experience for students (i.e., 30-79\% of course content is delivered online reflecting a mixture of online and face-to-face instruction; Allen \& Seaman, 2013).

An additional perspective coupled with the Core Competencies and Knowledge was the application of a conceptual framework for the program that included youth development theories, human development, youth program development, evaluation methods, and cultural and ethnic diversity. In addition to content courses to prepare professionals in the field of youth development, courses were included with the aim of preparing professionals who would have leadership competencies needed by youth-serving organizations (Garst et al., 2016). Therefore, additional courses included grant-writing, staff and volunteer recruitment and retention, and leadership skills and organizational development. Because the proposed curriculum reflected a graduate-level education, a statistics course and a program evaluation course were included as requirements of the graduate degree that would prepare professionals to both interpret and evaluate youth-related research and evaluation to enable them to assess program impact and 


\section{Advancing Academic Pathways}

processes and to contribute to valid policy and program decisions driven by their increased credibility among organizational and community leaders (Garst et al., 2018). Finally, a master's project capstone experience was originally embedded into the curriculum to provide students with an opportunity to conduct an independent research project pertaining to youth development under the guidance of a faculty advisor. Independent projects included, for example, examinations of vulnerable and under-resourced youth populations, program evaluations, community youth master plan initiatives, and environmental scans of youth wellbeing.

As the majority of M.S. YDL students do not aspire to research-related careers, the independent research project was made optional for students whose goal included seeking a doctoral degree, thus building research skills to be more competitive for such opportunities. In place of the two-course independent research project, two cutting-edge courses were added for most students whose professional goal was practitioner-based. The first course was a special topics course on contemporary issues in the field such as "youth development and nature" or "youth and technology." The second course added was a capstone course in which students build an electronic portfolio (e-portfolio) as a means for (a) synthesizing their substantive understanding of the literature in youth development and (b) organizing and reflecting on artifacts from across their courses in a way that best represents their growth as a youth development leader as well as a plan for their professional pathway forward. The e-portfolio can also serve as a job résumé for future use. Each instructor in the M.S. YDL program must build into a course syllabus an individual artifact to demonstrate independent work and a collaborative artifact reflecting teamwork. An individual artifact might include development of a logic model of a youth program, a paper on a theory of youth development, a grant proposal, or a youth program evaluation design. A collaborative artifact includes course activities such as a team project, a team class presentation, or a proposal of a best practice program. Also included in an eportfolio are a résumé, professional philosophy statement, and a final reflection scanning and synthesizing all program courses and experiences. Each student is assigned a faculty advisor to guide professionally written reflections of artifacts. The culmination of the e-portfolio is a comprehensive online exam in which the student presents the content of the e-portfolio to the graduate committee comprised of youth development faculty, and answers faculty questions relevant to specific course content.

A cohort model was used in which all students enrolled, who had been accepted into the program at the same time, would begin the first course together and then continue to complete 


\section{Advancing Academic Pathways}

their courses at the same time as a single group. This model was economically feasible to deliver each course in sequence, building one upon another. For example, the course Theories and Foundations of Youth Development is required as a first course in the degree program to provide all students with a strengths-based youth development framework from which to build competencies such as youth development program best practices; youth program evaluation designs; diversity in a global world; building staff and volunteers in youth-serving organizations; grant writing in the field of youth development; and leadership skills in youth-serving settings. In addition, the cohort model provided nontraditional students with opportunities to overcome geographical distance by building a professional network of like-minded professionals who could share their experiences and challenges with each other.

An additional program requirement was a 3-day new student on-campus orientation. During this visit, students would meet and get to know their classmates personally, meet the faculty, learn online education technologies from the computer center staff, and begin the first course. In addition, students completed community and team-building activities in an experiential camp setting associated with the university. A second-year 2-day required campus visit provides students with an opportunity to share their program evaluation projects in an on-campus graduate symposium poster session open to all department graduate students.

The YDL courses were offered in an accelerated format in which courses were taken consecutively with each course being 7 weeks long. Courses were structured according to a blended online coursework approach (Allen \& Seaman, 2013). A weekly 90-minute synchronous class was required in each course during which the instructor and students were engaged online in real time through the Adobe Connect platform. Instructors supplemented synchronous meetings in some courses with recorded lectures for students to review prior to the weekly meeting. Breakout rooms in weekly classes provided small-group class interaction. Student teams frequently made presentations to the class during these synchronous meetings. Whereas each faculty member created a unique structure for a course with varied activities, all instructors used the Blackboard or Canvas platform to incorporate weekly discussion board questions to encourage class interaction. Instructors assigned scholarly papers to facilitate critical thinking and administered quizzes or exams where appropriate to assess acquisition of knowledge. Two courses were completed each semester including summer sessions which allowed students to complete the required 12 courses in 6 semesters (or 2 years). Thus, the first YDL cohort graduated in December 2007, and between that time and December 2018, a total of 12 student cohorts or 176 students have completed a YDL M.S. degree. Additionally, 45 


\section{Advancing Academic Pathways}

graduate students received a YDL certificate only. Certificate graduate students enroll in the same courses as their M.S. degree counterparts, and obtain the credential after completing five courses. Certificate students are most often employed or volunteer in youth-serving organizations in which the goal is to build competencies embedded in youth development frameworks that can be implemented in their onsite work settings.

While online nontraditional programs such as Clemson University's YDL graduate program have grown (see U.S. Department of Education's Y4Y Career Models Initiative y4y.ed.gov for a list of programs), few have evaluated the impact of their programs in preparing youth development leaders to strengthen youth-serving organizations within communities. In general, evaluations of the program indicated $64 \%$ of graduates experienced new professional work opportunities and/or a raise in pay (Garst et al., 2016). Program evaluations also highlighted many benefits graduates experienced at the professional, programmatic, and community levels (Garst et al., 2018). Evaluations of the program have also documented specific features that students find most valuable.

\section{Program Features}

Graduates of the program come from varied academic backgrounds, with undergraduate degrees ranging from psychology and sociology to electrical engineering and mathematics. On average, they have been involved in youth work for about 18 years, both as paid employees and volunteers. Graduates consistently report four features of the blended online degree program most valuable in learning youth development frameworks and practices, and skill sets (e.g., features of best practice programs; evaluation methodologies; grant writing) (Garst et al., 2016). These features were: (a) 3-day on-campus new student orientation including meeting cohort members and faculty, learning online education technologies, beginning the first course on foundations of youth development, and team building; (b) the cohort model in which students build a support system of success for each other across all courses; (c) weekly synchronous meetings in each course using Adobe Connect to foster dissemination of instructor expertise, student and instructor discussion for critical thinking, and to manage course activities; and (d) relevant course content sufficiently grounded in strengths-based frameworks and building skill sets in areas such as youth program best practices, evaluation methodologies and procedures, and grant writing.

The first program feature that graduates found valuable was campus visits including the initial campus orientation and second-year visit. The itinerary for the new student campus orientation 


\section{Advancing Academic Pathways}

includes introductions of students and faculty, icebreakers, orientation to the degree program, learning online education technologies, outdoor team-building activities, a meeting with M.S. YDL graduates, and class time for the first course. The second-year visit includes individual student research/evaluation presentations to peers as part of the current course on youth program assessment and evaluation, participation in a graduate student research poster session, and a dinner banquet with student award presentations and a guest speaker in the field of youth development. The majority of YDL graduates also return for university commencement, though this campus visit is not required.

The second feature rated consistently high by graduates is the cohort model to foster academic support and meaningfulness of the course of study. Students (approximately 23 annually) enroll initially each August and participate in courses collectively (i.e., as a cohort), which provides social support and a higher level of application of concepts to their job settings as they can share programmatic and organizational successes and challenges using the lens of the academic content in which they are immersed at any given time (Shockley \& Thompson, 2012). In addition to social support and content application (Thompson \& Shockley, 2013), the cohort model also provides students a level of shared accountability to motivate sustained and qualityfocused performance (Stein et al., 2005).

The third feature rated consistently high is the weekly synchronous real-time class time of a minimum of 90 minutes using technology (e.g., Adobe Connect; Zoom) that provides instructor creativity and flexibility as well as a high level of student participation. Examples of weekly synchronous meeting activities include lectures, student team presentations, student and peer/instructor chat discussions, and small-group breakout assignments. Students consistently report that these class meetings provide stimulating discussion, the need to "think-on-yourfeet," benefit from the expertise of the instructor, and opportunities to give and receive peer support that increases success expectations and retention. Particularly beneficial is the opportunity for students who are working professionals to reflect on their real-world experiences, successes, and challenges in the youth-serving organization of which they are affiliated, to share, brainstorm, and apply content to these "boots on the ground" everyday work experiences. Such class discussions bolster their commitment to the degree program as they experience its value in potentially increasing their own job competencies and strengthening their organizations. 


\section{Advancing Academic Pathways}

The fourth highly-rated component of the M.S. YDL program reported by graduates was the course content which was considered empowering and unique to their work environments. Graduates reported discovering useful conceptual frameworks, skill sets, and a professionalism in youth development with which they heretofore were not familiar. The course content contributed to their new abilities to make valuable and unique contributions to their youth organizations and community partners in providing youth development programs. Students were empowered by such content to have a stronger voice in their professional network and build new partnerships (Garst et al., 2016).

Graduates of the M.S. YDL program report additional benefits which contribute to their professional development as youth development leaders. Some of these benefits include professional networking that facilitates job opportunities, a changed perspective of viewing youth development leadership as a career, and career advancement opportunities. In fact, there have even been a few cases in which student cohort members have assisted their peers in securing jobs related to the degree. This provides further validation of the value graduates place on their academic degree experience and growth. Graduates possessed a clearer identity as a youth development professional.

\section{Applications to Practice}

This paper reported on a well-established and empirically supported youth development academic degree program (Garst et al., 2016; Garst et al., 2018). Outcomes delineated the likelihood of strengthening the youth development workforce utilizing academic institutions and online learning technologies. Moreover, with evidence of the success of a youth development academic degree program, youth-serving organizations are now positioned to raise job standards and expectations of future employees. For example, youth development professionals holding specific positions or representing specific hierarchical levels within youth-serving organizations might be identified as employees particularly well-suited to the growth and development associated with a youth development leadership academic degree, such as middleto senior-level administrators, program leaders, evaluators, policy-makers, and others assigned for critical leadership functions. By doing so, the work force in the youth development arena will grow significantly stronger as employers can now expect that such job expectations can be met. As a result, youth-serving organizations become more meaningful and impactful in their communities and, in the end, youth in such communities uniquely benefit in achieving positive well-being and preparation for a successful adulthood. The institutionalization by youth-serving 
organizations of higher standards and expectations in future employee competencies have the potential to expand with the advent and growth of youth development degree programs when youth-serving organizations justifiably seek more competent youth development staff who will, in the aggregate, strengthen the work force and more broadly serve and enhance youth development in more communities.

\section{References}

Allen, I. E., \& Seaman, J. (2013). Changing course: Ten years of tracking online education in the United States (1 $1^{\text {st }}$ ed.). New York, NY: Babson Research Group and Quahog Research Group.

Asher, R. (2012). Human resources: Staffing out-of-school time programs in the $21^{\text {st }}$ century. Afterschool Matters, 16, 14-47.

Blattner, M. C., \& Franklin, A. J. (2017). Why are OST workers dedicated—or not? Factors that influence commitment to OST care work. Afterschool Matters, 25, 9-17.

Blyth, D. A. (2011). The future of youth development: Multiple wisdoms, alternate pathways and aligned accountability. Journal of Youth Development, 6(3), 165-180. https://doi.org/10.5195/JYD.2011.182

Borden, L. M., Craig, D. L., \& Villarruel, F. A. (2004). Professionalizing youth development: The role of higher education. New Directions for Youth Development, 104, 75-85. https://doi.org/10.1002/yd.100

Borden, L. M., Schlomer, G. L., \& Wiggs, C. B. (2011). The evolving role of youth workers. Journal of Youth Development, 6(3), 126-138. https://doi.org/10.5195/jyd.2011.179

Bowie, L., \& Bronte-Tinkew, J. (2006). The importance of professional development for youth workers. Child Trends, 17, 1-9. https://cyfar.org/sites/default/files/Bowie\%202006.pdf

Bradshaw, L. D. (2015). Planning considerations for afterschool professional development. Afterschool Matters, 21, 46-54.

Byrne, A. \& Hansberry, J. (2007). Collaboration: Leveraging resources and expertise. New Directions for Youth Development, 2007114), 75-84. https://doi.org/10.1002/yd.214

Cole, P. (2011). Building an afterschool workforce: Regulations and beyond. Afterschool Matters, 13, 1221. https://www.niost.org/pdf/afterschoolmatters/asm 201113 spring/asm 201113 spring2.pdf

Cooper, B. (2013). Teaching the what as well as the how: Content-rich OST professional development. Afterschool Matters, 18, 1-8. https://www.niost.org/2013-Fall/teaching-the-what-as-well-as-thehow-content-rich-ost-professional-development 
Deutsch, N. L., Blyth, D. A., Kelley, J., Tolan, P. H., \& Lerner, R. M. (2017). Let's talk after-school: The promises and challenges of positive youth development for after-school research, policy, and practice. In N. L. Deutsch (Ed.), After-school programs to promote positive youth development: Integrating research into practice and policy (p. 45-68). Springer Science + Business Media. https://doi.org/10.1007/978-3-319-59132-2 4

Dymnicki, A. B., Le Menestrel, S., Boyd, M. J., Lauxman, L., Oberlander, S. E., \& Osher, D. M. (2016). Developing a federal research agenda for positive youth development: Identifying gaps in the field and an effective consensus building approach. Journal of Youth Development, 11(1), 5-19. https://doi.org/10.5195/jyd.2016.430

Finn-Stevenson, M. (2014). Family, school, and community partnerships: Practical strategies for afterschool programs. New Directions for Youth Development, 144, 89-103. https://doi.org/10.1002/yd.20115

Gabrieli, C. (2011). The emergence of time as a lever for learning. New Directions for Youth Development, 131, 43-54. https://doi.org/10.1002/yd.407

Garst, B. A., Baughman, S., \& Franz, N. K. (2014). Benchmarking professional development practices across youth-serving organizations: Implications for Extension. Journal of Extension, 52(5), 1-13. https://www.joe.org/joe/2014october/a2.php

Garst, B., Bowers, E., Quinn, W., \& Gagnon, R. J. (2016). Building pathways from research to practice: Preparing youth development professionals through an online master's degree program. In K. M. Pozzoboni and B. Kirshner (Eds.), The changing landscape of youth work: Theory and practice for an evolving field (pp. 91-108). Charlotte, NC: Information Age.

Garst, B., Weston, K., Bowers, E., \& Quinn, W. (2018). Fostering youth leader credibility: Professional, organizational, and community impacts associated with completion of an online master's degree in youth development leadership. Children and Youth Services Review, 96, 1-9.

https://doi.org/10.1016/j.childyouth.2018.11.019

Gerdes, J., Durden, T. R., Mincemoyer, C. C., \& Lodl, K. (2013). Preparing adults to work with youth: An environmental scan of professional development. Journal of Youth Development, 8(2), 15-28. https://doi.org/10.5195/jyd.2013.93

Hall, G., Poston, K. F., and Dennehy, J. (2017). Summer learning programs: Investigating strengths and challenges. In N. L. Deutsch (Ed.) After-school programs to promote positive youth development, advances in child and family policy and practice. https://doi.org/10.1007/978-3-319-59141-4_1

Johnson, E., Rothstein, F., \& Gajdosik, J. (2004). The intermediary role in youth worker professional development: Successes and challenges. New Directions for Youth Development, 104, 51-64. https://doi.org/10.1002/yd.98 
Journal of Youth Development | http://jyd.pitt.edu/ | Vol. 15 Issue 1 DOI 10.5195/jyd.2020.814

Advancing Academic Pathways

Khashu, A. \& Dougherty, N. L. (2007). Staffing practices of high-quality after-school programs. Houston, TX: Cornerstones for Kids.

Leos-Urbel, J. (2015). What works after school? The relationship between after-school program quality, program attendance, and academic outcomes. Youth and Society, 475) 684-706. https://doi.org/10.1177/0044118X13513478

Lerner, J. V., Bowers, E. P., Minor, K., Boyd, M. J., Mueller, M. K., Schmid, K. L., . . Lerner, R. M. (2013). Positive youth development: Processes, philosophies, and programs. In R. M. Lerner, M. A. Easterbrooks, \& J. Mistry (Eds.); I. B. Weiner (Editor-in-Chief), Handbook of psychology: Developmental psychology (Vol. 6, pp. 365-392). Hoboken, NJ: Wiley.

Mahoney, J. L. \& Warner, G. (2014). Issue editors' notes. New Directions for Youth Development, 144, 110. https://doi.org/10.1002/yd.20108

National AfterSchool Association (NAA). (2019). Core Knowledge and Competencies. Retrieved from https://naaweb.org/resources/core-competencies

Ravazi, S. (2007). The political and social economy of care in a development context: Conceptual issues, research questions, and policy options (Gender and Development Programme Paper Number 3). Geneva, Switzerland: United Nations Research Institute for Social Development. http://www.unrisd.org/80256B3C005BCCF9/(httpAuxPages)/2DBE6A93350A7783C12573240036D 5A0/\$file/Razavi-paper.pdf

Richardson, M. S. (2012). Counseling for work and relationship. Counseling Psychologist, 40(2), 190-242. https://doi.org/10.1177/0011000011406452

Roth, J. L., \& Brooks-Gunn, J. (2016). Evaluating youth development programs: Progress and promise. Applied Developmental Science, 20(3), 188-202. https://doi.org/10.1080/10888691.2015.1113879

Shockley, C. \& Thompson, A. (2012). Youth workers in college: A replicable model for professional development. Children and Youth Services Review, 34(4), 735-739. https://doi.org/10.1016/j.childyouth.2011.12.019

Simpkins, S. D., Riggs, N. R., Ngo, B., Vest Ettekal, A. \& Okamoto, D. (2017). Designing culturally responsive organized after-school activities. Journal of Adolescent Research, 32(1), 11-36. https://doi.org/https://doi.org/10.1177/0743558416666169

Stein, J. A., Wood, E., Walker, J. A., Kimball, E. M., Outley, C. W., \& Baizerman, M. (2005). The youth development leadership experience: Transformative, reflective education for youthwork practitioners. Child and Youth Care Forum, 34(4), 303-325. https://doi.org/10.1007/s10566-0054096-5 
Journal of Youth Development | http://jyd.pitt.edu/ | Vol. 15 Issue 1 DOI 10.5195/jyd.2020.814 Advancing Academic Pathways

Stonehill, R. M., Lauver, S. C., Donahue, T., Naftzger, N., McElvain, C. K., \& Stephanidis, J. (2011). From after-school to expanded learning: A decade of progress. New Directions for Youth Development, 131, 29-41. https://doi.org/10.1002/yd.406

Thompson, A. \& Shockley, C. (2013). Developing youth workers: Career ladders for sector stability. Children and Youth Services Review, 35(3), 447-452.

https://doi.org/10.1016/j.childyouth.2012.12.019

U.S. Department of Education. (n.d.). You for youth. Online professional learning and technical assistance for $21^{\text {st }}$ century community learning centers. Retrieved from https://y4y.ed.gov/professionalization-resources/institutions-of-higher-education-contacts/

Yohalem, N., Pittman, K., \& Moore, D. (2006). Growing the next generation of youth work professionals: Workforce opportunities and challenges. Houston, TX: Cornerstones for Kids. 